\title{
Alcohol dehydrogenase of Drosophila melanogaster: metabolic differences mediated through cryptic allozymes
}

\author{
Pieter W. H. Heinstra, \\ Wim J. M. Aben, Willem Scharloo \\ and George E. W. Thörig
}

\begin{abstract}
Department of Population and Evolutionary Biology, University of Utrecht, Padualaan 8, $3584 \mathrm{CH}$ Utrecht, The Netherlands.
\end{abstract}

Acetone formation from propan-2-ol, a saturated secondary alcohol, has been analysed in flies of three different Adh-genotypes of $D$. melanogaster. The in vivo oxidation of propan-2-ol was mainly mediated through ADH activity. It could be demonstrated that flies homozygous for the $A d h^{71 k}$ allele produced more acetone than flies homozygous for $A d h^{F}$. This difference in metabolic flux mediated through the cryptic allozymes under non-saturated ADH-substrate conditions seems to be based on their different kinetic properties in vivo. Product inhibition of ADH monitored by means of ADH-isozymes conversion as observed after electrophoresis was similar for both cryptic allozymes.

ADH-71k and ADH-F showed immunological identity, and the in vivo protein levels of ADH-71k were 25-30 per cent higher than ADH-F.

The population-genetic implications of our findings have been evaluated.

\section{INTRODUCTION}

The alcohol dehydrogenase locus $(A d h$, II-50·1) of Drosophila melanogaster is polymorphic in natural populations (van Delden, 1982). Natural populations generally contain three allelic forms, $A d h^{F}, A d h^{S}$, and $A d h^{71 k}$ (probably identical to $A d h^{F C h . D}$ and $A d h^{F r}$, see Gibson et al., 1980). Gel electrophoresis has been used to detect their alcohol dehydrogenase protein products $(\mathrm{ADH}$, EC 1.1.1.1.), ADH-F, ADH-S, and ADH-71k, respectively. The ADH-F and $\mathrm{ADH}-71 \mathrm{k}$ allozymes show identical electrophoretic mobility, however, they differ in several fysico-chemical properties (Thörig et al., 1975; Eisses et al., 1985). Moreover, population-genetic studies have shown that a natural substrate of $\mathrm{ADH}$, ethanol, exerts selective pressure on the allele-frequences, favouring $A d h^{71 k}$ over $A d h^{F}$ (Scharloo et al., 1977). The functional significance of this variation for individuals still remains an open question when the precise metabolic function of ADH has not been unravelled.

Recent studies have demonstrated a dual, sequential function of $\mathrm{ADH}$ in primary alcohol degradation (Heinstra et al., 1983 and 1986a; Eisses et al., 1985; Geer and McKechnie, 1984; Moxom et al., 1985). The failure of $\mathrm{ADH}$ to oxidise secondary alcohols by means of such a two-step mechanism is caused by the formation of ketone end-products which form inhibitory dead-end ternary complexes with ADH and NAD (Heinstra et al., 1986a). This effect can have consequences for variation in $\mathrm{ADH}$ activity, because increasing levels of $\beta$-keto compounds affect the ratio between the fully-active $\mathrm{ADH}-5$, the half-active $\mathrm{ADH}-3$ and the inactive $\mathrm{ADH}-1$ isozyme in vivo (Heinstra et al., 1986b).

It has been assumed that the variation in $\mathrm{ADH}$ activity causes functional differences in metabolic flux and affects the acute toxic effects of the alcohols present in natural habitats (David and van Herrewege, 1983; McKechnie and Morgan, 1982; van Delden, 1982). However, recent studies of Middleton and Kacser (1983) have shown no close relation between variation in in vitro $\mathrm{ADH}$ activity caused by different $A d h$ genotypes and the in vivo flux measured as carbon dioxide and lipid product formation. Such whole flux measurements from ethanol as precursor may provide insight into the ultimate significance of $\mathrm{ADH}$ activity variation to control the flux to both end-products. On the other hand, the one-step oxidation of secondary alcohol substrates by $\mathrm{ADH}$ allows a direct estimate of action of the enzyme variants (Heinstra et al., 1986a).

We report here differences in oxidation rates of the secondary alcohol, propan-2-ol, into acetone between flies homozygous for different $A d h$ alleles. 


\section{MATERIALS AND METHODS}

\section{Strains and rearing of flies}

Three strains of D. melanogaster were studied. Two strains were homozygous for the world-wide common $A d h^{F}$ and the less-common $A d h^{71 k}$ allele, respectively. The alleles were extracted from two different Notch/delta-49 strains $\left(A d h^{F}\right.$ from an $N^{f a j 24 a}$ and $A d h^{71 k}$ from an $N^{8}$ strain). Both strains were maintained for several years in similar wildtype backgrounds (see Eisses et al., 1985). As a reference, the $A d h^{f n 23}$ strain was used which is homozygous for the purple ( $p r)$ and cinnabar (cn) eye-colour mutants. Flies of this strain completely lack $\mathrm{ADH}$ activity, but show $\mathrm{ADH}$ protein levels, due to a 34 base pairs deletion within exon III of the Adh gene (Benyajati et al., 1983). Flies were reared on cornmeal medium $(1300 \mathrm{ml}$ water, $10 \mathrm{~g}$ agar, $200 \mathrm{~g}$ cornmeal, $100 \mathrm{~g}$ sugar, $12 \mathrm{~g}$ dead yeast, $10 \mathrm{ml} 10$ per cent nipagine in ethanol) at $25^{\circ}$. Adult males aged for 6.5 days $( \pm 12 \mathrm{hr}$ ) after emergence were used throughout this study. During ageing flies were transferred to fresh food media after 3.5 and $5 \cdot 5$ days, to remove endogenous ethanol which was often found to be present in the $A d h^{f n 23}$ flies.

\section{In vivo studies}

Fifteen males were exposed to vapour of propan-2ol in a closed glass-vial at $25^{\circ}$ and 60 per cent R.H. Flies were prevented from sucking the propan-2-ol by separation of the flies from the solution present in cotton-wool (see details, Heinstra et al., 1986a), by means of a small strip of cotton-wool which was permeable to vapours. When needed, flies were removed from the vials and immobilised immediately by a cold-treatment of $5 \mathrm{sec}$ at $0^{\circ}$. Two series of five males were homogenised at $100 \mu \mathrm{l}$ ice-cold pure water. Homogenates were kept cold and within $10 \mathrm{~min}, 1 \mu \mathrm{l}$ aliquots were analysed by means of gas chromatography (for details, see Heinstra et al., 1983 and 1986a). Extracts of control flies contained neither propan-2-ol nor acetone.
Homogenization of control flies of each $A d h$ genotype in ice-cold $10 \mathrm{mM}$ propan-2-ol did not generate acetone. Within the period of in vivo metabolism, excretion of propan-2-ol and acetone has not been found. The data given here are representative for various independent analyses performed during two months involving four subsequent generations of flies.

Levels of propan-2-ol and acetone in the fly extracts were calculated by means of peak height $x$ relative retention time. Standards of known concentrations of both compounds served as references for the peak heights. Concentrations of the compounds per fly were obtained after multiplying by the dilution factor ( 20 times per fly) and the mean fresh body weights (see table 1 ).

\section{Electrophoresis}

The procedures of slab-gel and gel-disc electrophoresis are given by Heinstra et al. (1983 and $1986 \mathrm{~b}$ ). In all cases, $10 \mu \mathrm{l}$ of independent fly extracts ( 5 males homogenised in $100 \mu \mathrm{l} 50 \mathrm{mM}$ phosphate-buffer $p \mathrm{H} \mathrm{6.7)} \mathrm{were} \mathrm{applied.} \mathrm{The} \mathrm{stain-}$ ing solution after slab-gel electrophoresis consisted of $100 \mathrm{mM}$ ethanol, $0.23 \mathrm{mM}$ NAD (Boehringer, Mannheim, FRG, Grade I), 1.5 mM MTT (Serva, Heidelberg, FRG) and $1 \mu \mathrm{M}$ PMS (Sigma, St. Louis, U.S.A.) in a $50 \mathrm{mM}$ phosphate-buffer $p \mathrm{H}$ 7.4. Staining lasted for one $\mathrm{hr}$ at $25^{\circ}$ in the dark. Staining for gel-discs used, $13 \mathrm{mM}$ propan-2-ol and $0.15 \mathrm{mM}$ NAD in a $50 \mathrm{mM}$ phosphate-buffer $p \mathrm{H} 7.4$ for $30 \mathrm{~min}$ at $25^{\circ}$ in the dark. Activity of the ADH-isozymes was visualised under ultraviolet illumination $(\lambda=366 \mathrm{~nm})$.

\section{Antibody production}

Purified ADH-F protein (for the purification procedure, see Eisses et al., 1985) containing approximately $1 \mathrm{mg}$ ADH per ml was mixed with Freund's complete adjuvant in a $1: 1$ ratio, and $4 \mathrm{ml}$ were injected subcutaneously into New Zealand white

Table 1 Kinetic parameters from the two ADH-allozymes

\begin{tabular}{lllll}
\hline & $\begin{array}{l}\text { Mean fresh } \\
\text { male body } \\
\text { weight }(\mathrm{mg})\end{array}$ & $\begin{array}{l}\boldsymbol{V}_{\max } \\
(\mu M \text { product/min/fly })\end{array}$ & $\begin{array}{l}{[S]_{0.5}} \\
(\mu M)\end{array}$ & $V_{\text {max }} /[S]_{0.5}$ \\
\hline$A d h^{71 k / 71 k}$ & $0.813 \pm 0.049$ & $390.5 \pm 24.5$ & $313.1 \pm 20.5$ & 1.25 \\
$A d h^{F / F}$ & $0.755 \pm 0.023$ & $168.0 \pm 49.0$ & $178.9 \pm 55.9$ & 0.94 \\
$\boldsymbol{A d h}^{\text {fn23 }}$ prcn & $0.784 \pm 0.049$ & - & - & - \\
\hline
\end{tabular}

Mean fresh body weights were determined from thirty flies of each genotype and do not show significant differences (Student's $t$-test). $[S]_{0.5}$ values given are those at endogenous substrate levels. 
rabbits. After three weeks the rabbits were bled. After centrifugation, the pelleted blood cells were suspended in $4 \mathrm{ml} 0.9$ per cent $\mathrm{NaCl}$ and again centrifuged. After some washes with 0.9 per cent $\mathrm{NaCl}$, two volumes of the final solution were mixed with one volume of purified ADH-F protein. After a two-hour incubation period at room temperature, the rabbits were boosted with $3 \mathrm{ml}$ of this solution. A week later, the animals were bled again and after centrifugation, the antiserum was stored in small aliquots at $-25^{\circ}$.

\section{Immunological characterisation}

First, characterisation was done by immunodiffusion using the method of Ouchterlony (1953). In order to obtain the relative in vivo $\mathrm{ADH}$ allozyme quantities, radial immunodiffusion gels were run according to Mancini et al. (1965). Homogenates were obtained after homogenization of 4 or 5 males in $100 \mu l$ water and centrifugation for $20 \mathrm{~min}$ at $6000 \mathrm{rpm}$ and $4^{\circ} .5 \mu \mathrm{l}$ of the resulting supernatant were placed in $2 \mathrm{~mm}$ wells in 1 per cent $(\mathrm{w} / \mathrm{v})$ agarose -1 per cent $(\mathrm{v} / \mathrm{v})$ antiserum immunodiffusion gels. After developing for $20 \mathrm{hr}$ at $4^{\circ}$, the gels were stained for $\mathrm{ADH}$ activity and the ring diameters measured by means of a BioradRad immunodiffusion reader. The amount of ADM is expressed in radical immunodiffusion units relative to the $\mathrm{ADH}-71 \mathrm{k}$ allozyme.

\section{RESULTS}

The $A d h^{71 k}$ and $A d h^{F}$ alleles were brought into similar wild-type backgrounds (Eisses et al., 1985) which might have affected the original manifestation of their ADH allozymes (e.g., Maroni et al., 1982). However, in complete accordance with previous results (Thörig et al., 1975), crude extracts of ADH-71k showed higher activity on ethanol than ADH-F (fig. 1(a)). Moreover, the difference in temperature-sensitivity has also been sustained. ADH-71k was more active, whereas ADH-F partially lost its activity after a heat-shock in vitro (fig. 1(b)).

Exposing flies to increasing levels of propan-2ol revealed in vivo acetone product levels as depicted in the figs. $2(\mathrm{a}-\mathrm{c})$. It is evident that at each substrate level, flies homozygous for $A d h^{71 k}$ produced more acetone than those homozygous for $A d h^{F}$. From measurements of flies without active ADH protein $\left(A d h^{f n 23}\right)$, it can be deduced that the acetone product formation in both genotypes with $\mathrm{ADH}$ activity was mainly mediated by $\mathrm{ADH}$. Therefore, in the initial periods, the formation of
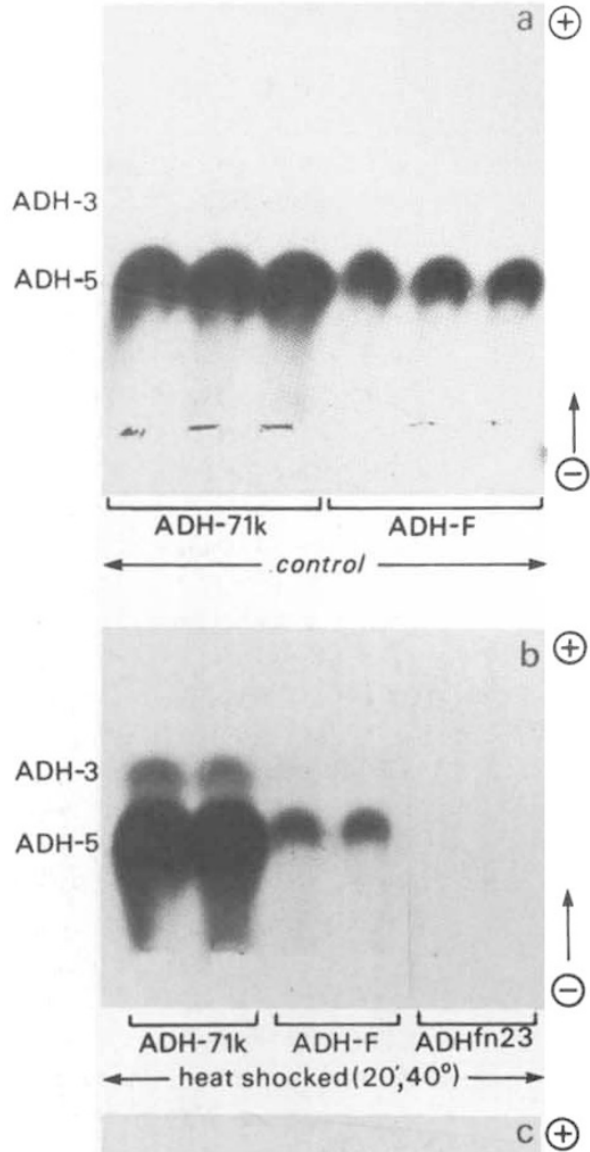

$\mathrm{c} \oplus$

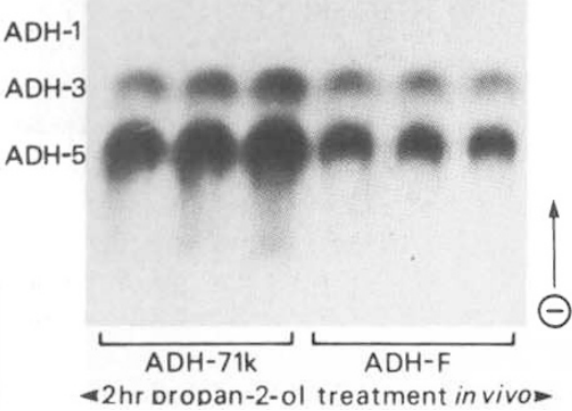

Figure 1 Electrophoretogram stained with the MTT-formazan method. (a), control flies. (b), after application of a heatshock of the gel. (c), flies exposed to $260 \mathrm{mM}$ ( $=2$ per cent $\mathrm{v} / \mathrm{v})$ propan-2-ol.

acetone not mediated by ADH can be neglected in both ADH-active genotypes. The initial rates of product formation $(v)$, as determined from the time zero till $30 \mathrm{~min}$ periods (figs. $2(\mathrm{a}-\mathrm{c})$ ), have been plotted according to Lineweaver-Burk $(1 / v$ vs. $1 /[\mathrm{S}]$, see fig. $2(\mathrm{~d}))$. From two independent 

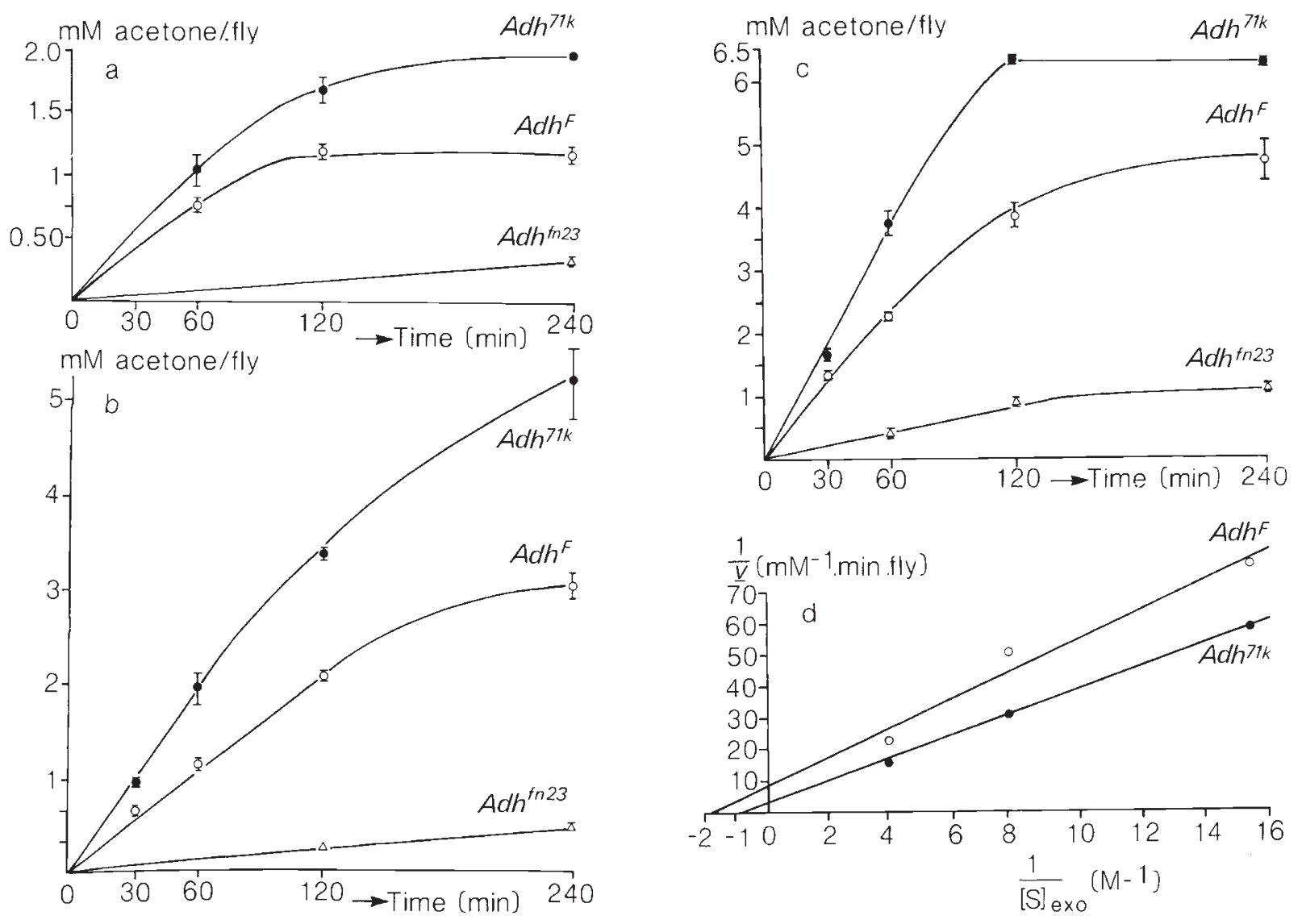

Figure 2 Metabolism of propan-2-ol in vivo. (a-c), acetone formation in time at different exogenous liquid-phase propan-2-ol levels. (a), at $65 \mathrm{mM}(=0.5$ per cent v/v) propan-2-ol. (b), at $130 \mathrm{mM}$, and (c), at $260 \mathrm{mM}$. Bars indicate standard errors, $\mathrm{n} \geqq 4$. (d) Lineweaver-Burk plots derived from the curves shown in $(\mathrm{a}-\mathrm{c})$ which illustrate the regression of reciprocal values of $v$ against those of exogenous substrate levels.

plots (the other was over the $0-520 \mathrm{mM}$ substrate range), the kinetic parameters, maximum velocity $\left(V_{\max }\right)$ and the substrate concentration that yields half the maximum velocity $\left([\mathrm{S}]_{0.5}\right)$, were determined (table 1). It turns out that the ADH-71k allozyme shows on the average higher values of $V_{\max }$ as well as of $[S]_{0.5}$ when compared with ADH-F.

The in vivo data also allow an analysis of the rates of total propan-2-ol uptake (sum of endogenous propan-2-ol and acetone, table 2). It is found that both $\mathrm{ADH}$-active genotypes had uptake rates of vapours which are nearly identical (non-significant differences in the Student's $t$-test). Comparable pictures have been obtained at the other substrate levels. Moreover, these data also indicate that per min time interval about 0.02 per cent of the propan-2-ol liquid had entered the fly as vapour. This has been used to transform the $[S]_{0.5}$ values at exogenous levels into their respec- tive endogenous substrate levels (see table 1 for final data).

The administration of propan-2-ol to flies and larvae results in a conversion of the electrophoretic ADH-isozymes pattern (e.g., Schwartz and Sofer, 1976; McKechnie and Geer, 1984). This effect is visualized in the figs. 1 (c) vs. 1(a) and fig. 3 , based

Table 2 Uptake rates of propan-2-ol vapours

\begin{tabular}{llc}
\hline & \multicolumn{2}{c}{ Genotype } \\
\cline { 2 - 3 } Time (min) & $A d h^{F / F}$ & $A d h^{71 k / 71 k}$ \\
\hline 30 & $1 \cdot 71 \pm 0.05$ & $1.66 \pm 0.09$ \\
60 & $3 \cdot 63 \pm 0.25$ & $3 \cdot 74 \pm 0.22$ \\
120 & $5 \cdot 74 \pm 0.35$ & $6 \cdot 32 \pm 0.08$ \\
240 & $7 \cdot 10 \pm 0.05$ & $7 \cdot 28 \pm 0.08$ \\
\hline
\end{tabular}

The data represent the sum of endogenous propan-2-ol and acetone $(\mathrm{mM} / \mathrm{fly})$ as determined at $260 \mathrm{mM}$ exogenous levels of propan-2-ol. 


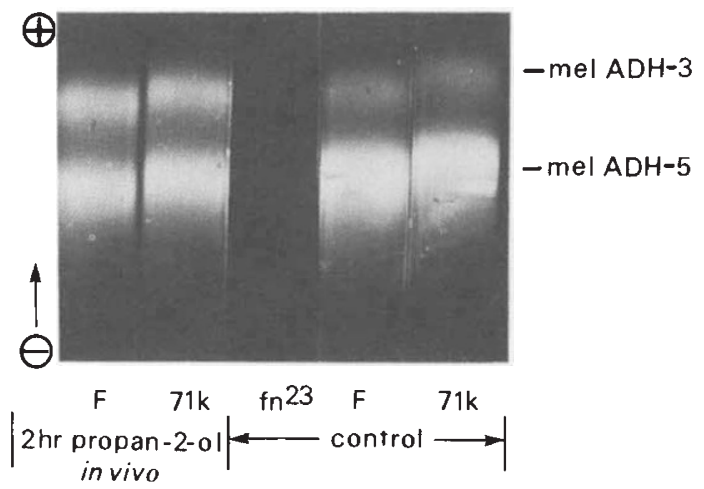

Figure 3 Electrophoretogram visualised by means of NADH fluorescence. For details, see fig. 1(a) and 1(c).

on two different methods of staining (Heinstra et $a l ., 1985 b)$. The conversion patterns show that the $\mathrm{ADH}-5 / \mathrm{ADH}-3$ isozyme activity ratio remained similar for both cryptic allozymes.

Immunological characterisation according to Ouchterlony (1953) indicated that crude extracts of $A d h^{F}$ and $A d h^{71 k}$ flies and an aliquot of ADH-F and ADH-71k purified protein gave single and continuous precipitin lines without spurs with antiADH-FF serum (data will be published in detail elsewhere). This provided evidence for immunological identity between the two ADH-allozymes. It also suggested that the antigen in the fly-extract was the same as the purified ADH-protein. Further immunological studies according to the radial immunodiffusion method showed the linear relationship between the ring diameter and the log of the relative enzyme concentration $(r=0.997)$ from serial dilutions of an extract of $A d h^{71 k}$ flies (fig. 4(a)). Furthermore, it turned out that in vivo

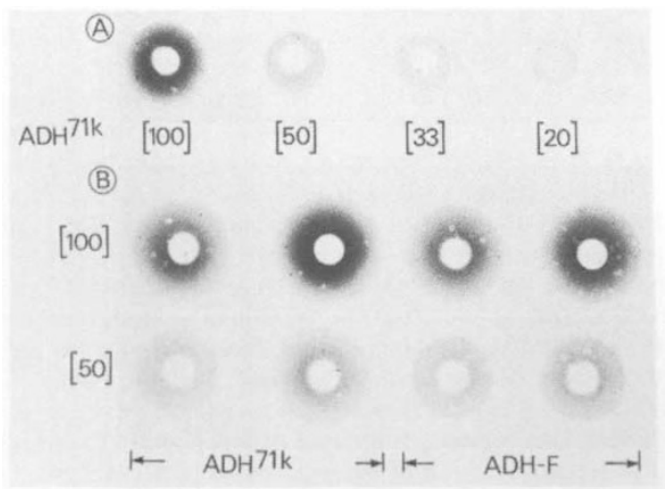

Figure 4 Immunological characterization. Panel A. Serial dilution of crude $A d h^{71 k}$ extract. Panel B. Differences in $\mathrm{ADH}$ allozyme protein levels from undiluted and diluted extracts. levels of ADH-FF protein were 25-30 per cent lower than the ADH-71k71k in their respective homozygous male flies (fig. 4(b)), table 3).

Table 3 Immunological characterization

\begin{tabular}{lc}
\hline Allozyme & $\begin{array}{l}\text { Relative in vivo } \\
\text { protein levels }\end{array}$ \\
\hline ADH-FF & $73 \pm 0.7$ \\
ADH-71k71k & $100 \pm 1.9$ \\
\hline
\end{tabular}

* Significantly different from ADH-71k71k, $P<$ $0.01(n=8)$.

\section{DISCUSSION}

Catabolism of propan-2-ol in vivo has been found to be mediated mainly through $\mathrm{ADH}$ activity (see also Heinstra et al., 1986a). The two genotypes with $\mathrm{ADH}$ activity, and with similar genetic backgrounds, had nearly identical uptake rates of substrate vapours. Nevertheless, flies homozygous for $A d h^{71 k}$ produced more acetone than those homozygous for $A d h^{F}$. Therefore, it can be concluded that under comparable in vivo conditions, the ADH-71k allozyme determines a higher metabolic flux than its cryptic ADH-F counterpart.

Metabolic flux mediated by an enzyme is the net result of several parameters e.g., enzyme quantity, kinetic mechanism and properties, and substrate, coenzyme and product levels. Increase of substrate levels resulted in a proportional increase of product formation (fig. 2(a-c)), which implies first-order conditions. This indicates that the ADH molecules in vivo were not saturated with substrate. Under such conditions, the in vivo differences between the $\mathrm{ADH}$-allozyme levels would be a minor factor to determine the differential flux (Segel, 1975, p. 41). When it is assumed that $\mathrm{NAD}^{+}$-coenzyme levels were non-limiting (Heinstra et al., 1986a), these findings allow the determination of some kinetic properties. However, it should be mentioned that the in vivo system deviates from the usual in vitro assays (see Segel, 1975, pp. 46-48 and p. 83). The $V_{\max }$ and $[S]_{0.5}$ values determined as such, do show considerable differences between the two $\mathrm{ADH}$ allozymes (table 1). This suggests that substitution of one amino acid in the primary sequence affects kinetic properties of an allozyme (see Eisses et al., 1985 for further discussion). Further, it suggests that the flux differences have been generated by the net differences in kinetic properties.

The calculated $V_{\max }$ values, though-ADH-71k shows 25-30 per cent more protein in vivo than 
ADH-F, remain tentative, because product inhibition must also be considered. Drosophila-ADH forms strong inhibitory dead-end ternary complexes with NAD and ketones during the oxidation of secondary alcohols (Heinstra et al., 1985a and references therein). Moreover, this type of product inhibition, which occurs despite a TheorellChance mechanism (Winberg et al., 1982; Hovik et al., 1984), might be followed in time as the concomitant conversion of the electrophoretic ADH-isozymes pattern (Heinstra et al., 1985b). The conversion patterns for the two cryptic ADHallozymes suggested similar relative rates of product inhibition.

Differences in fitness can be anticipated when different activities of the ADH-allozymes cause different accumulation patterns of alcohols in the body. Our in vivo findings (see also, Heinstra et al., 1985a) combined with those of David et al. (1981) indicate that propan-2-ol is more toxic than acetone which contrasts previously held opinions. In mammals, propan-2-ol exerts effects on the acidbase status, glucose homeostasis, and lipid metabolism in the cells (Kricka and Clark, 1979). Moreover, alcohols are neurotoxic which might account for the loss of locomotor ability of genotypes without $\mathrm{ADH}$ activity during exposure to ethanol (Grell et al., 1968) and to propan-2-ol (figs. 2(a-c); P. Heinstra, unpublished observations). The relationship between the metabolic stress and fitness depends on the effective levels of alcohols entering the individuals and the metabolic transformation of these alcohols and their direct products. We have shown that only a fraction of the propan-2-ol liquid enters the fly as vapour. Despite the different volatilities of alcohols in general, it can be expected that the potential selective action of alcohols present in natural habitats (McKechnie and Morgan, 1982; Briscoe et al., 1975 ) is rather small in adults. Larvae, however, crawl in fermenting liquids and ingest the alcohols. Under such conditions, already low exogenous substrate levels may reach endogenous levels far above concentrations which saturate ADH. This suggests that the relation between functional differences of ADH allozymes in alcohol metabolism and metabolic stress, and ultimate differences in fitness is more important in larvae than in adults.

In conclusion, an one-step catabolism has been employed to determine metabolic flux mediated through ADH allozymes. It remains to be shown whether the observed differences are also representative for the putative two-step function of $\mathrm{ADH}$ allozymes in degradation of primary alcohols. Insight into this issue must await the results of further in vivo studies which are in progress.

Acknowledgements We are indebted to Dr W. Sofer (State University of Piscattaway, USA) for providing the $A d h^{f n 23}$ strain. We also thank Mrs Els Kruitwagen (Laboratory of Chemical Animal Physiology, University of Utrecht) for providing the GLC facilities, and Drs Karel Eisses, D. Holwerda and Albert Klarenberg for valuable discussions. Drawing and phototechnical work were performed by $\mathrm{Mr}$ Dick Smit, $\mathrm{Mr}$ Cees Strijland and Mr Piet Brouwer.

\section{REFERENCES}

BENYAJATI, C., PLACE, A. AND SOFER, w. 1983. Formaldehyde mutagenesis in Drosophila: Molecular analysis of ADHnegative mutants. Mutation Res., 111, 1-7.

BRISCOE, D. A., MALPICA, J. M. AND ROBERTSON, A. 1975. Dominance at the Adh locus in response of adult Drosophila melanogaster to environmental alcohol. Nature, $255,148-149$.

DAVID, J. R., VAN HERREWEGE, J., SCHEEMAEKER-LOUIS, M. AND PLA, E. 1981. Drosophila alcohol dehydrogenase: Detoxification of isopropanol and acetone, substances not used in energy metabolism. Heredity, 47, 263-268.

DAVID, J. R. AND VAN HERREWEGE, J. 1983. Adaptation to alcoholic fermentation in Drosophila species: Relationship between alcohol tolerance and larval habitat. Comp. Biochem. Physiol., 74A, 283-288.

EISSES, K. TH. SCHOONEN, W. G. E. J., ABEN, W., SCHARLOO, W. AND THÖRIG, G. E. W. 1985. Dual function of the alcohol dehydrogenase of Drosophila melanogaster: Ethanol and acetaldehyde oxidation by two allozymes ADH-71k and ADH-F. Mol. Gen. Genet., 199, 76-81.

GEER, B. W. AND MCKECHNIE, S. W. 1984. Dietary ethanol and lipid synthesis in Drosophila melanogaster. Genetics, 107, $s 36$.

GIBSON, J. B., CHAMBERS, G. K., WILKS, A. V. AND OAKESHOTT, J. G. 1980. An electrophoretically cryptic alcohol dehydrogenase variant in Drosophila melanogaster. I. Activity ratios, thermostability, genetic localization and comparison with two other thermostable variants. Aust. J. Biol. Sci., 33, 387-398.

GRELL, E. H., JACOBSON, K. B. AND MURPHY, J. B. 1968. Alterations of genetic material for analysis of alcohol dehydrogenase isozymes of Drosophila melanogaster. Ann. N.Y. Acad. Sci., 151, 441-455.

HEINSTRA, P. W. H., EISSES, K. TH., SChOONEN, W. G. E. J., ABEN, W., DE WINTER, A. J., VAN DER HORST, D. J., VAN MARREWIJK, W. J. A., BEENAKKERS, A. M. TH., SCHARLOO, W. AND THÖRIG, G. E. W. 1983. A dual function of alcohol dehydrogenase in Drosophila. Genetica 60, 129-137.

HEINSTRA, P. W. H., EISSES, K. TH., SCHARLOO, W. AND THÖRIG, G. E. W. 1986a. Metabolism of secondary alcohols in Drosophila melanogaster: Effects on alcohol dehydrogenase. Comp. Biochem. Physiol., 83B, 403-408.

HEINSTRA, P. W. H., SCHARLOO, W. AND THÖRIC, G. E. W. 1986b. Alcohol dehydrogenase of Drosophila: Conversion and retroconversion of isozyme patterns. Comp. Biochem. Physiol., 83B, 409-414.

HOVIK, R., WINBERG, J-O. AND MCKINLEY-MCKEE, J. S. 1984. Drosophila melanogaster alcohol dehydrogenase: Substrate stereospecificity of the $\mathrm{Adh}^{\mathrm{F}}$ alleloenzyme. Insect. Biochem., 14, 345-351. 
KRICKA, L. J. AND CLARK, P. M. S. 1979. Biochemistry of Alcohol and Alcoholism. John Wiley \& Sons. New York.

MANCINI, G., CARBONARA, G. O. AND HEREMANS, J. F. 1965. Immunochemical quantification of antigens by single radial immunodiffusion. Immunochemistry, 2, 235-254.

MARONI, G., LAURIE-AHLBERG, C. C., ADAMS, D. A. AND WILTON, A. N. 1982. Genetic variation in the expression of ADH in Drosophila melanogaster. Genetics, 101, 431436.

MCKECHNIE, S. W. AND MORGAN, P. 1982. Alcohol dehydrogenase polymorphism of Drosophila melanogaster: Aspects of alcohol and temperature variation in the larval environment. Aust. J. Biol. Sci., 35, 85-93.

MCKECHNIE, S. W. AND GEER, B. W. 1984. Regulation of alcohol dehydrogenase in Drosophila melanogaster by dietary alcohol and carbohydrate. Insect. Biochem., 14, 231-242.

MIDDLETON, R. J. AND KACSER, H. 1983. Enzyme variation, metabolic flux and fitness: alcohol dehydrogenase in Drosophila melanogaster. Genetics, 105, 633-650.

MOXOM, L. N., HOLMES, R. S., PARSONS, P. A., IRVING, M. G. AND DODDRELL, D. M. 1985. Purification and molecular properties of alcohol dehydrogenase from Drosophila melanogaster: Evidence from NMR and kinetic studies for function as an aldehyde dehydrogenase. Comp. Biochem. Physiol., 80B, 525-535.
OUCHTERLONY, O. 1953. Antigen-antibody reactions in gels. IV Types of reactions in coordinated systems of diffusion. Acta Pathol. Microbiol. Scand., 22, 231-240.

SCHARLOO, W., VAN DIJKEN, F. R., HOORN, A. J. W., DE JONG, G. AND THÖRIG, G. E. W. 1977. Functional aspects of genetic variation Christiansen, F. B. and Fenchel, T. M. (eds.) In Measuring Selection in Natural Populations. Springer. Berlin.

SCHWARTZ, M. AND SOFER, w. 1976. Diet-incuced alterations in distribution of multiple forms of alcohol dehydrogenase in Drosophila. Nature, 263, 129-131.

SEGEL, I. H. 1975. Enzyme kinetics. John Wiley \& Sons. New York.

THÖRIG, G. E. W., SCHOONE, A. A. AND SCHARLOO W. 1975. Variation between electrophoretically identical alleles at the alcohol dehydrogenase locus in Drosophila melanogaster. Biochem. Genet., 13, 721-731.

VAN DELDEN, W. 1982. The alcohol dehydrogenase polymorphism in Drosophila melanogaster: Selection at an enzyme locus. Evol. Biol., 15, 187-222.

WINBERG, J-O., THATCHER, D. R. AND MCKINLEY-MCKEE, J S. 1982. Alcohol dehydrogenase from the fruitfly, Drosophila melanogaster: Substrate specificities of the alleloenzymes $\mathrm{Adh}^{\mathrm{S}}$ and Adh ${ }^{\mathrm{UF}}$. Biochem. Biophys. Acta., 704, 7-16. 